\title{
NATO Enlargement and Beyond
}

\section{Edwin J. Pechous *}

The direction of NATO's future security posture currently hangs in the balance. Efforts for a modest increase in new membership and an expansion of interests and cooperation beyond its present day borders continue unabated. Where this policy will lead is yet to be determined. It is certainly worthwhile for those involved in this planning and strategy development in the next years to pursue a deeper understanding of the most recent enlargement processes from the mid-1990s to 2004-when ten new members entered the Alliance - and the overall NATO/U.S. outreach efforts during the same period of expansion. Our analysis of these endeavors is based on the insight gained from the conduct of 105 conferences with various combinations of the 26 PFP members led by a team from the Institute for Defense Analyses under the sponsorship and guidance of the George C. Marshall Center and the U.S. Department of Defense.

Considerable value can be gained by scrutinizing the factors involved in the success of the most recent enlargement process and examining what worked, why it succeeded, how it was approached, who made it happen, where was it focused, and when progress was made. In addition, this paper provides analyses of NATO from a slightly different perspective, focusing on NATO's continuing enlargement program and its extended outreach efforts.

The reshaping of the Eurasian security alliances following the end of the Cold War remains uncompleted, with potential for success if pursued adroitly and based on the past principles that marked the accession of the ten newest members. The key development to date has been the expansion of the North Atlantic Treaty Organization (NATO) to a continent-wide Alliance, with a European membership of twenty-four nations subscribing to a commitment to collective defense. Full national incorporation of southeastern European countries into NATO structures has proceeded at a modest pace. The central and most perplexing issues facing the Alliance are how to ensure security on its eastern and southern perimeters and how to decide on the nature and extent of its military and security outreach beyond these boundaries. In supporting the accession of ten new members from the 1990s to 2004, NATO proceeded on the assumption that these states' incorporation into Europe's collective security apparatus would be underpinned by comprehensive political, economic, and societal reform in each of the aspirant nations. Remarkably, this approach succeeded in all ten of the new member countries. Not surprisingly, such lofty goals for future expansion in areas east and south from the NATO frontier ridgeline appear to be a somewhat dim prospect. A look at how the process of European security realignment evolved and how it progressed will help clarify how those inside NATO and those on the outside affected by NATO conceived of their relationships and reacted to these conceptions.

Edwin J. Pechous is a retired senior U.S. government official currently working with the Institute for Defense Analyses in Alexandria, VA. 


\section{Post-Cold War NATO Membership Enlargement}

Statesmen and senior government officials, including George C. Marshall, Secretary of Defense William Perry, the late Congressman Gerald Solomon, and others concerned with the viability and future of NATO over the decades have urged that the U.S. support policies of broad inclusion to help create harmony on a European continent that had seen little other than war, conflict, chaos, and bickering for nearly 1600 years since the demise of the Pax Romana. NATO's consolidation and modest expansion in the forty years from 1950 to 1990 established a precedent for further inclusion, which led to the rapid enlargement process of the 1990s and the early twenty-first century. This opened the path to building an even stronger foundation for the creation of an expanded NATO, with the goal of a Pax Europa with strong North American participation and a fundamental stability. While the physical changes to the Alliance occurred on the European continent, the affirmation of North American commitment was defined in Richard Holbrooke's 1995 article in Foreign Affairs, "America, a European Power." 1

In Norfolk, Virginia, on 27 June 1996, Secretary of Defense William Perry outlined the key requirements for those seeking NATO membership. Since the primary driver for enlargement of NATO was the U.S., most of the aspirants carried on a dialogue with the U.S. in parallel to their dialogue with NATO, and promoted in both conversations their advocacy for membership. Perry declared that:

Military forces of the new members must be capable of operating effectively with NATO forces. This means not only a common doctrine, but interoperable equipment-especially communications equipment. And potential new members must uphold democracy and free enterprise, respect human rights inside their borders, and respect sovereignty outside their borders, and their military forces must be under democratic, civilian control. $^{2}$

NATO's requirements for admission proved not to be mere guidelines. Instead, they took the form of absolutes that directed the nearly decade-long accession process. Interestingly, certain aspects of Perry's and others' pronouncements appeared to recognize a lack of unanimity of acceptance among active NATO members, particularly with respect to free enterprise. Nonetheless, they proceeded with these tenets as absolutes. Not surprisingly, the military expectations often proved less complex for candidates to meet, except for those nations with long traditions of established general staff leadership. In these nations, the degree of civilian control and direction of the military general staff remained contentious; this discord extended beyond officials' recognition of enlargement needs. These difficulties, centering on the very nature of national mili-

1 Richard Holbrooke, “America, a European Power,” Foreign Affairs (March/April 1995): 38 51 .

2 U.S. Secretary of Defense William J. Perry, "Six Postulates for a Future NATO," prepared remarks delivered to the Supreme Allied Commander, Atlantic, Seminar, Norfolk, Virginia, 27 June 1996; published in Defense Issues 11:56, and available at www.defenselink.mil/ speeches/speech.aspx?speechid $=995$. 
tary organization principles, often were coupled with the problems associated with significant troop reductions.

\section{The Enlargement Record and its Import}

Why the NATO enlargement process worked so well-succeeding beyond the expectations of most of those involved - should be clearly understood by the planners, policy decision-makers, and strategists plotting the future shape of the NATO security architecture. At the same time, the understanding gained from the expansion experience provides a picture of the dilemmas NATO faces in setting its future course. The main successful achievements of NATO's recent expansion process were underpinned by the following factors:

- NATO members had a baseline understanding of the extent and degree of NATO hegemony

- NATO members agreed informally that enlargement of membership was being driven by desires for stability creation rather than force enhancement

- Aspirant nations had an absolute belief that the protection of Article V provisions of the NATO charter was central to their future national integrity

- There was accord among the members and aspirants that certain military, political, and economic principles guided and controlled the accession process

- The NATO enlargement process was aspirant-driven and -led

- NATO enlargement was a factor enhancing the support and encouragement of European economic and political unity

- All security, including NATO's, was and will be affected heavily by the many facets of the twenty-first-century dynamic, including globalization, information diffusion, the nature of warfare, and the ascendancy of science and technology

- NATO members cautiously avoided the premature accession of new members to prevent forming NATO ties and commitments with a potential "failed state"

- NATO members assisted in finding, defining, and enabling niche roles for the newly accepted member nations

- All of the successful NATO applicants exhibited a strong determination to use Western examples and experience in restructuring their institutions and societies.

Following the end of the Cold War, NATO struggled with articulating the reasons for expanding its membership. As a result, the initial pace of enlargement was slow and halting, and the extent was limited. The U.S., as the engine of the Alliance, was struggling to define its own security future, including the extent and degree of worldwide hegemony it might exercise either alone or through the NATO Alliance. As the events of 2001 to 2006 clearly showed, the far-reaching, rather aggressive path the U.S. selected has prompted mixed responses among its NATO allies. One result, perhaps by design, has been a deliberately vague strategy regarding expansion on the part of both the U.S. and NATO. At the same time, new NATO members have provided the U.S. 
with additional leverage within the Alliance, but often at the expense of the support of a number of the more established Western European members. To date, the United States' use of its leadership role in NATO to extend its hegemony has been limited by NATO rules assigning individual veto powers to each member nation on most issues. There has been increasing resentment in some NATO quarters of the repeated U.S. unilateral military and security actions in recent years. Despite sporadic disagreements with NATO's older members, the ten new NATO nations have almost unanimously supported the U.S.'s strong lead role in the organization, which they see as serving and upholding international security. There is less certain support for U.S. actions in other situations, such as Iraq, from most of the other sixteen NATO members. Both the old and the new NATO members have been influenced by the relative magnitude of the military force capabilities of the U.S., the former less than the latter.

\section{Stability over Force Enhancement}

A veteran U.S. colonel who had spent most of his adult life fighting the battles of the Cold War to an honorable end scowled in a conversation at a 1995 meeting at NATO headquarters, at which serious questions had been posed about both the enlargement concept and the initial formulating actions taking place at the time. He expressed his views clearly, to the effect that enlargement would weaken rather than strengthen NATO. The military force of the Alliance would be diluted, and in the long run NATO would suffer. Six years later, as he moved toward retirement, he admitted that his view had changed; he had realized that the force enhancement issue was a "sideline" that would take care of itself. The rewards of a stabilized, peaceful, conflict-free Europe bolstered by new member enlargement far outweighed any small diminution of force capabilities. Put bluntly, the aspirants in the mid- and late 1990s primarily were being admitted not to create additional military strength, but to assist in forming a common European security baseline that would ensure intra-European conflict avoidance and give the Alliance the consensus authority, both moral and material, to maintain a completely stable Europe.

\section{Article V: A Central Role}

Preservation of national integrity was at the top of the list in all aspiring member states' delineations of national objectives. The ten countries in NATO's fifth and sixth accession lists in 1999 and 2004 had all faced decades of occupation or subordination to outsiders. With the end of the Warsaw Pact and the independence of numerous formerly Soviet republics, each of these nations was determined to ensure that a threat to its national integrity would not arise again. At the same time, they were also convinced that they did not and would not possess the military strength necessary to fully ensure their continued unhindered sovereignty. Article V, binding members of NATO to come to each other's defense when attacked, soon became their holy grail. ${ }^{3}$ Led by the Baltic states (and supported by the first wave of new members: the Czech Republic, Hungary, and Poland), who had increasing fears of a loss of national identity in the last days of

3 NATO Treaty of 1949, Article V. 
the Soviet Union, the aspirants were continually at NATO's doorstep urging rapid acceptance of new members and expansion of NATO's security architecture and influence.

The key to this ultimately successful drive was persistence, consistency, and total confidence in the certainty of the shelter of Article $\mathrm{V}$ as the key ingredient in meeting their critical security needs. This approach served as a generator for the full membership of some nations (such as Georgia) that are located geographically beyond NATO's then existing perimeter in Europe. By 2006, the muted urgency of this cohesive force had diffused, and the interests of those outsiders who were engaged in dialogue with NATO became more diverse and less focused. Thus, from 2004 to 2007, ambivalence and uncertainty on the part of the NATO leadership about their version of the near abroad have increased.

\section{Energizing Factors in Membership Expansion}

With the figurative bronze plaque of membership emblazoned in the minds of proponents in aspirant nations, NATO's rules for admission became the sine qua non, requiring full compliance by prospective members if they were to be admitted. By the mid-1990s, it appeared that the transition and transformation measures required for admission might exceed the capabilities of many of the aspirant nations. They were expected to change dramatically, not only militarily, but also politically and economically; in addition, they were being asked to completely revamp their civil society. This transformation was not easy, and the necessary reforms were often painful, requiring sacrifice and astute leadership. It is fair to say that without the impetus of transformation as a key to membership acceptance, many positive developments - such as new national security strategies and fiscal control by democratically elected legislaturescould have fallen by the wayside or never have been considered, and the necessary changes, which also paved the parallel road to European Union (EU) expansion, might never have transpired with the necessary robustness.

\section{Leadership by the Aspirants}

The support for the initiatives and the energy leading to NATO enlargement were, for the most part, far stronger among the aspirants than they were among the existing membership. The enlargement process worked, and the NATO architecture strengthened, because of the near single-minded motivation of the ten nations seeking admission. An early case in point was the absolute determination of the three Baltic statesEstonia, Latvia, and Lithuania - to secure membership and push forward in their efforts despite numerous rebuffs and discouragements, at times both from within NATO generally and unilaterally from the U.S., for reasons that appeared sound at the time. However, the Baltics finally wore down the opposition within NATO and gained full U.S. support, despite the opposition of those concerned over the possible negative impact of Baltic admission on the evolving Russian equation in East-West and international security matters. 
This strong, single-minded commitment to NATO membership was found in all aspirant nations, and ultimately generated new life and energy for the Alliance as a whole. These developments also reaffirmed that the dynamics created by this bottomup approach not only strengthened the NATO security architecture, but also gave credence to its policy goals, and proved far more effective in building regional stability than organizations such as the United Nations, which necessarily had to rely for the most part on a top-down approach based on issue-by-issue consensus to execute effective actions.

The interest of the NATO aspirants for parallel EU inclusion was immediate and positive. For the decade or more since 1993, the ten nations pursuing NATO membership also undertook to be included in an expanded EU and a European-centered economic zone. It became clear early on that most new NATO aspirants considered the EU a vital part of their future economic well being; many, however, had less enthusiasm for an enhanced political role for the EU. The NATO aspirants of the 1990s believed that, although EU membership was desirable, full NATO membership was essential. The value and protection provided by inclusion in NATO appeared to them central to their newly perceived national interests; for these potential NATO members, the role and commitment of the U.S. remained a dominant factor, with inclusion in the EU important, but clearly secondary.

\section{Impact of the Broad Nature of Security in the Twenty-First Century Dynamic}

The NATO accession process in the decade from 1994 to 2004 set the stage for the aspirant nations becoming aware and understanding that national security encompasses all aspects of national strength, not only military power. This realization encouraged new members to reform, transition, and transform nearly all aspects of their national governments and their dealings with neighbor states and the Alliance. Understanding and adapting to the overriding effects of globalization, information diffusion, economic changes, and the ascendancy of science and technology became a paramount concern. More slowly and less dramatically, a nuanced interpretation of national security evolved as the accession process proceeded, and a modified, broader view developed among established members of NATO as well.

A less positive aspect of this altered outlook was the tendency of many key established members of NATO to rationalize their growing neglect of commitments to military expenditures. These nations have increasingly used this "new grasp" of the nonmilitary aspects of national security to justify casual disregard of their military responsibilities, gradually eroding NATO's military response capabilities and the national commitments of resources to NATO's military capabilities. This trend has accelerated in recent years, often compounded by a fractured view of the nature of the threats and challenges to the NATO security architecture.

Despite the differing views of defense responsibility among the NATO members, the immediate impact of NATO enlargement, particularly with respect to stability, has affected regions not generally seen as having an immediate future as part of the Alliance. The spirit and influence of the NATO enlargement process flowed over into such efforts as attempts to reduce tension in Bosnia-Herzegovina. An initial Marshall Center 
outreach course in 1998 addressing the economic and institutional foundations of prosperity was followed by two seminars in 1999 aimed at ameliorating the difficulties in the former Yugoslav country with discussions and workshops dealing first with defense resource planning, and then followed by a seminar on confidence building in a defense reduction environment. These seminars, co-sponsored by the Marshall Center and the Organization for Security and Cooperation in Europe, achieved limited cooperation among the participants in an open and cooperative exchange of opinions about the respective defense positions adopted by the country's factions. The first seminar, held in Salzburg, Austria, led to agreement on a 30 percent reduction in defense expenditures. At the conclusion of the second seminar, the parties adopted recommendations for a declaration on defense reductions to be supported by the international community's aid in bringing demobilized military personnel into broader societal and economic involvement.

\section{Concerns over the Enlargement Process}

In NATO's initial exploration in 1992 and 1993 of the key issues it faced in dealing with enlargement, even among those favoring a rapid pace, there was serious concern over the potentially disastrous consequences of admission of a state whose efforts to transform might ultimately fail. As a result, some backers of enlargement during this period provided only cautious support. Other concerns included not only the possibility that enlargement would lead to a dilution of NATO's military strength and cohesiveness, but also possible reactions by post-Soviet Russia, which might lead to a reversal of the gains made after the end of the Cold War. Another concern was that a NATO troubled by enlargement woes might ultimately lead the U.S. to retreat to "Fortress America," particularly if any of the newly proposed members became serious problems. This concern led NATO to refuse Slovenia admission in 1997, when it appeared well prepared to meet qualifications for the first round. As a result, NATO delayed the country's entry until the second round in 2004, when it (along with the other remaining six candidates for 2004) completed a closely monitored and controlled accession compliance process.

This careful approach by NATO, although difficult, paid dividends. The ten new members have consistently proven their mettle. Beyond 2004, the entry procedures for those next in line - the Balkan states of Croatia, Albania, and Macedonia - have been guided by the same careful NATO compliance process. These three nations over the years not only have made changes and reforms related to their own internal situations, but have also demonstrated that they can meet all NATO standards and pose no danger of becoming recidivists.

\section{Incorporating Niche Roles for New Members}

Since providing some kind of force enhancement was one of several main requirements for aspirant nations pursuing NATO accession, many potential members had to overcome significant resource limitations to meet the military contribution requirements. As the membership dialogue progressed, it became clear that a state's ability to make a useful but limited military input to NATO's overall military needs was essential. The 
aspirant nations had to outgrow their initial inclination to promise NATO complex and expensive contributions in their effort to prove their worthiness for inclusion. At the outset, NATO understood the need for discrimination in military resource commitments far better than did those seeking admission. Complicating this aspect of an evolving joint NATO-aspirant planning dialogue was the simultaneous major military downsizing process that was going on in many of the former Warsaw Pact applicants. The first-wave members, as well as Slovakia, Bulgaria, and Romania among the second, had substantial military forces and were slashing their numbers at a significant pace. At the other extreme, the Baltic states and Slovenia were not downsizing; instead, they were basically building military forces from scratch. In both instances, however, there was a need to find a proper balance between making military contributions to NATO and keeping their military expenditures affordable so that they did not overburden other key aspects of the reform process.

\section{A Functioning and Adaptive NATO}

By 2004, the enlargement process - with many accommodations, and considerable effort by all concerned - had basically achieved NATO's goal of creating a more broadbased and extended European-North Atlantic security architecture. The question then became, What next? The response in 2004 was the dual move of selective pursuit of a handful of new potential members within NATO's traditional European geographic boundaries, primarily in Southeastern Europe, and an exploration of ways to expand security by extending NATO ties to a number of nations beyond the Alliance's perimeter. This latter effort has proven to be a most vexing challenge. The central concern was to define Europe geographically within the NATO Charter to determine a fit under the new circumstances. This issue has yet to be addressed directly. In the original NATO Charter, Europe is defined, by inference at least, as ending at the Bosporus Strait. Other core issues, such as whether the Caucasus and Central Asian countries are a part of Europe, must be determined. At the same time, NATO itself has to determine whether extending new types of relationships or a modified form of membership to those nations on or beyond its perimeter is practical, feasible, or advantageous to the organization and its security interests. For a multitude of reasons related to expansion - including security, cultural, economic, and political as well as military-NATO must take a position and provide a clear understanding to those within its own ranks as well as to potential partners outside Europe. At the moment, clarity is lacking among all concerned.

\section{Diffusion or Concentration?}

The primary challenge that NATO's planners and policy-makers are confronting about the future path of the organization is focus. Should NATO concentrate its efforts on the nations on its perimeter, or should it take a more diffused approach, forging ad hoc security arrangements with nations beyond Europe's geographic boundaries? Within Europe, perimeter nations that are potential areas of focus include Croatia, Albania, Macedonia, Ukraine, Moldova, Bosnia-Herzegovina, Montenegro, and Serbia. In fo- 
cusing on these perimeter nations, NATO would increase its efforts to enhance their opportunities for membership. On the other hand, if NATO takes the diffuse approach, it would extend its attention and assess the various options on its perimeters and beyond. To date, NATO's focus appears to be divided. NATO is currently conducting as yet unproven experiments to expand collaboration through the Individual Partnership Action Plan process and various other forms of interactive dialogue with non-European states. Directions and decisions, which are usually dictated by the individual national interests of the major established members of NATO, have yet to be firmed up, leading to uncertainty and apparent wasted efforts. A fully articulated policy that fosters consistent strategies in the future is needed to replace the current process, in which NATO summit pronouncements are both the arbiter and instigator of future expansion of the organization's security interests.

From the onset of the enlargement process in the early 1990s, NATO, with U.S. leadership, made it absolutely clear that any aspirants for NATO membership must accept and implement all measures necessary to meet the standards and norms inherent in NATO. This uncompromising stance, while at times difficult for the aspirant nations, provided a course for moving the membership dialogue forward, shaping policies, and implementing actions.

The process resulted in the successful admission of the ten new members by 2004 . Without the foundation of a jointly agreed upon, broad-based set of norms, extending the dialogue to additional new nations has been complicated by both the actions and policies of NATO and its dialogue partners. NATO's requirement for the new partners' full commitment to NATO principles - such as democratic governance, civilian democratic control of the military, and market economies - now appears to be more flexible in this newly extended dialogue on security cooperation. This revised NATO approach has allowed regional cooperative exchanges to flourish (at least in volume, if not in substance). However, without the previous firm underpinning of clear principles and demands, NATO's enlargement after 2004 has lost specific purpose, and has resulted in only marginal progress. The total commitment and responses demanded of the recently admitted ten aspirants to NATO membership, which succeeded so well, appear to have been ignored to a degree in the new extended partnership discussions. As a result, NATO has been hesitant in its planning and wavering in its strategy on expansion, and finds itself committed to further interaction without specific goals or expected results.

Any future change in the NATO security architecture to accommodate and incorporate new players requires a sound understanding and appreciation of the key factors underlying a yet-to-be-achieved broader stability. A major complication is that in the decade from 1994 to 2004, NATO was dealing with secular states in developing democratically oriented societies. Energized by the events since 9/11, the green wave of fundamentalist Islam, intolerant of secularism and with significant popular support in some areas in Europe, has strongly influenced or controlled the security posture of many NATO perimeter states. Governments of many of these nations, with a secularism and leadership imposed by their Soviet past, are struggling to retain control, and not necessarily by completely democratic means. The external push from the U.S. and 
NATO to open these contested governments to broader public participation often leads to a majority determinism of uncertain direction, or to the extension of the "one man, one vote, one time" principle. In the same vein, the leadership in many of these nations still awaits clarification from the NATO Alliance on the nature and degree of cooperation, support, and collaboration expected of them, as well as on the extent of the perceived single-mindedness of NATO (or at least the U.S.) in the pursuit of its war on terrorism. Despite a myriad of interested parties, particularly in the Caucasus and Central Asia, there is still no consensus on the many elements of security policy and cooperative measures necessary to address key challenges of integrating these so-called outreach states into NATO.

\section{NATO Support to Perimeter Nations}

Increasing NATO's security through the extension of its perimeters has intrinsic value and a clear appeal. However, the necessary manner, will, resources, and capabilities of successfully accomplishing this objective appear less than certain now and for the foreseeable future. NATO's various outreach programs have not in recent years proven to be as fruitful as the most recent NATO membership enlargement process. Accession, which could include full NATO membership, continues to be mentioned in passing in NATO's dialogue with a few perimeter nations, but appears at best a remote possibility for any of them. Defining the appropriate level of cooperation and collaboration that should exist among NATO and the outreach parties remains difficult. At the same time, the question of direction and concentration remains a difficult challenge for NATO. With an ever diminishing resource base for defense and security among NATO's European members, will the Alliance be able to support a major outreach program while continuing to close the gap in its security architecture caused by the absence of nine key states in Southeastern Europe (Albania, Bosnia-Herzegovina, Croatia, Kosovo, Macedonia, Moldova, Montenegro, Serbia, and the Ukraine)?

A second issue remains on the table regarding the scope of NATO's outreach efforts beyond its perimeter. Should its goals, processes, and activities continue to focus on its core values for ensuring security - for example, democracy, market economies, respect for human rights - or should it concentrate on the more pragmatic elements that help support regional stability, such as enhanced capabilities to maintain public order? Both approaches have been tried, and both continue today, with no single path at the moment being favored.

Clearly there needs to be more precise agreement on priorities and direction in the outreach strategy within NATO, particularly between the U.S. and its European counterparts, on the direction and scope of Alliance efforts to expand its security horizons and interests. Although NATO currently sponsors a wide-ranging outreach program, many individual activities lack depth or follow-up because of the understandable limitations on funding and supporting resources. A more precise definition of future focus for this dialogue would benefit both NATO and its potential partners. 


\section{Migration: An Upcoming Quandary}

NATO's leaders have yet to address a second rarely discussed, but monumental, challenge facing the European component of the Alliance: migration. The continent's population is becoming increasingly older, and most European countries have a reduced or negative native population growth. Europe is faced on its southeastern and southwestern frontiers with an expanding populace seeking any means of entry into the prosperous European economy, particularly through immigration, legal or otherwise. In the past year, the European reaction to these developments has been one of expediency, doubt, and neglect. Expanded external migration into Europe is increasingly provoking opposition, resentment, and hostility among the citizenry while governments struggle to cope. In the next decade, as this problem continues to grow, fester, and become more serious, many Europeans will no doubt be tempted to draw upon the national security forces of NATO for perimeter control to curtail an increasing flow of illegal immigration, including whatever exclusionary measures might be necessary. When and if such a critical point is reached, an unwillingness on the part of the U.S. to become involved in this contentious issue, based in the argument that it lies outside of the legitimate sphere of NATO's obligations and responsibilities, could very likely cause considerable strain on the Alliance. Nonetheless, the potential erosion of stability by unchecked migration will make constructing new and expanding existing security relationships near or on the European perimeter much more difficult. Efforts to expand NATO interests, if not to enlarge its membership, will face new and increasingly difficult obstacles.

\section{Fissures and the Future}

The success of the NATO enlargement process of the last decade has had only minimal carryover to measures being taken to meet the many new challenges NATO faces. Cases such as the operations in Afghanistan, which enjoy broad support among NATO members, are counterpoised by the much more narrowly supported operation in Iraq. These have led to widely differing perceptions among the twenty-six NATO members on the extent and nature of any further expansion of the Alliance's interests. Key contentious issues such as the NATO-Russia relationship, the geopolitical order of the Near East (particularly related to dealing with the Israel question), and relations with conservative monarchies such as Saudi Arabia have yet to find consensus. Agreement on the overall extent of NATO outreach and expansion has barely scratched the surface of common attention in the organization. All in all, the next two decades will determine the likelihood of a long-term, coherent NATO strategy on enlargement and expansion being developed. Several key questions must be considered. Should NATO consolidate its remarkable gains of the past decade of enhancing stability in Europe through orderly and effective membership enlargement and assume more modest goals of concentrating on completing the purely European circle of membership by including the absent eight nations of Croatia, Albania, Macedonia, Ukraine, Moldova, Bosnia-Herzegovina, Montenegro, and Serbia? Or should it drive forward to incorporate a strategy of diverse and broad inclusion in the hopes of forging a meaningful, extended buffer 
between the "core" NATO nations and the many threats on the Alliance's perimeter and beyond? Needless to say, the latter course is uncertain and cluttered with a variety of dangerous pitfalls, including the will to support such an extension and the resource commitment necessary to succeed.

\section{NATO's Ridgeline}

Certainly, the key development in the broad sweep of NATO enlargement to date has been its expansion to become a truly continent-wide alliance, with a NATO European membership subscribing to collective defense. Full national incorporation of Southeastern Europe into the NATO structure proceeds at a modest but optimistic pace. The central and perplexing issues facing the Alliance center on how to ensure security on its eastern and southern perimeters and to decide on the nature and extent of its military and security outreach beyond these perimeters. NATO, in supporting the accession of ten new members from the decade of the 1990s to 2004, proceeded on the assumption that such new memberships would be underpinned by a required comprehensive political, economic, and societal reform in each of the aspirant nations. Although this approach succeeded, such lofty goals for any future expansion - not to mention membership enlargement - for regions east and south of the NATO frontier ridgeline, might appear to be beyond realization. A close look at the evolving European security realignment of the past fifteen years and how it progressed might help create a better understanding for those inside NATO as well as those on the outside affected by the Alliance.

Viewing the outward world from within its current perimeter, NATO's planners and policy makers today are facing numerous difficult questions. What should be the extent and nature of their outreach efforts? As a result of circumstance and inertia, continuing the successful path of the past decade's experience of NATO enlargement has been appealing and appears to be holding sway. Theater security cooperation between NATO and its potential partners beyond the perimeter continues apace. Although these exchanges between NATO and its potential partners have, for the most part, been relegated to more restrictive forms such as Individual Partnership Action Plans (IPAPs), lurking beneath the surface of the dialogue has been an unspoken belief both of some NATO members and of some designated partner nations that these current interactions could ultimately lead to an expanded membership.

Grappling with the sub rosa new membership issue has at times led the NATO military and civilian bureaucracy to pursue courses of action not backed by the concurrent underpinning of norms and standards that were the key to the success of the last ten NATO admissions. NATO's extensive interaction with nations outside its perimeter through a variety of exchanges, training exercises, and other forms of assistance has found a welcome reception but limited success. Essentially, each of the new potential partners on the NATO perimeter has failed to meet one or more of the key criteria that NATO in its past accession process found essential. The likelihood of permanent, across-the-board political, economic, cultural, security, and military reform in most of these nations is uncertain, and, at best, many years in the future. Extending a NATO hand to the process of overall reform risks NATO involvement in a potentially dam- 
aging outcome of supporting a failing or failed state. In the past few years, NATO's attention has turned more and more to dealing with non-military aspects of change in its outreach efforts.

Based on the enlargement lessons garnered over the past decade and insights gained from our work with the aspirant nations, it would appear more prudent and effective for NATO at this time to narrow its goals and expectations in countries beyond its perimeter, principally to helping build a solid security environment and functional militaries in the nations capable of sustaining internal balance and stability. Forces with the competence to support and ensure public order and public sustenance would enhance not only their own nation's security, but also their region's and NATO's as well. NATO's assistance might best be directed toward transition and transformation, primarily fostering in the military partners a new sense of national mission, an enlightened leadership, a firm sense of identity, and an across-the-ranks, non-corrupt character. Focusing attention on this limited strategy might serve NATO and its partners far better than the diffused and ambitious stance currently being considered, and, at times, pursued.

At the same time, closing the circle of full membership for those eight countries (or nine if Kosovo is to be included) could profitably be pursued, if an increased effort were made to enable these states to follow the same course with respect to NATO's membership requirements as the one that led to the last ten members' accession. NATO, without a Balkan doughnut hole in its Southeastern European flank, would indeed have a stronger and more solid security architecture, and would be better prepared to foster and effect more dramatic security changes in the coming decades. NATO enlargement in the past fifteen years has been a true success story, and new developments being fostered by NATO should add to it, as long as the leadership asks and answers the key questions facing them: Where are we? Where are we going? How are we going to get there? Sensible answers are essential in today's environment.

The year 2008 finds the NATO Alliance at a critical juncture. Retreating defensively behind the walls of its geographic and Alliance perimeter is generally considered unacceptable. NATO's outreach efforts to date have been hampered by the lack of a clear perception and consensus among the nations as to the nature and extent of such efforts and their overall value in enhancing the NATO security architecture. Bringing together the visions, policies, strategies, and resource commitments for a cohesive approach to the future among NATO as a whole, a NATO driven by a U.S. leadership role and dynamic, and the U.S. as a superpower engaged in a "war" on terrorism is a daunting task, but it must be accomplished to ensure a stable, if imperfect, world in the decades to come. 
SUMMER 2008

\section{Bibliography}

Holbrooke, Richard. "America, a European Power." Foreign Affairs (1995): 38-51. 